\title{
Ethylammonium-Selective Membrane Electrode Using p-tert-Butylcalix[6]arene Derivatives
}

\author{
Takashi KATSU ${ }^{\dagger}$ and Kazuyuki IDo \\ Faculty of Pharmaceutical Sciences, Okayama University, Tsushima, Okayama 700-8530, Japan
}

(Received October 15, 2001; Accepted February 1, 2002)

\section{Introduction}

Calixarenes have been successfully used to construct ionselective electrodes for primary organic ammonium ions as well as alkali metal cations. ${ }^{1,2}$ The hydrophobic cavities generated by the aromatic walls of phenol residues are potentially useful for the inclusion of non-polar moieties of alkylammonium ions..$^{3-7}$ In 1993, Chan et al. ${ }^{4}$ reported that calix[6]arenehexaacetic acid hexaethyl ester is an excellent ionophore for a primary alkylammonium ion, especially hexylammonium. This ionophore, named amine ionophore I (see the structure in Fig. 1), soon became commercially available from Fluka. ${ }^{8}$ Later, it was found to induce a strong response to methylammonium among primary ammonium ions., ${ }^{910}$ Thus, this compound primarily acted as a methylammonium ionophore. Chan et $a l .{ }^{4}$ also reported that the corresponding p-tert-butylcalix[6]arene derivative was less effective as a hexylammonium ionophore, probably due to a steric hindrance from the bulky tert-butyl groups. However, several calix[5]arene derivatives, having a smaller hydrophobic cavity than calix[6]arene derivatives, still showed a strong ability to recognize one of the primary organic ammonium ions, butylammonium, in spite of the presence of bulky tert-butyl groups. ${ }^{5}$ It was tempting to speculate that the p-tert-butylcalix[6]arene derivative, previously reported not to work as an effective hexylammonium ionophore, ${ }^{4}$ may recognize a certain specific primary alkylammonium ion other than hexylammonium. We thus examined the effects of two $p$ tert-butylcalix[6]arene derivatives, p-tert-butylcalix[6]arenehexaacetic acid hexaethyl ester (2) and p-tertbutylthiacalix[6]arene-hexaacetic acid hexaethyl ester (3), shown in Fig. 1, and compared them with amine ionophore I (1). Derivative $\mathbf{2}$ was used previously by Chan et al. ${ }^{4}$ while $\mathbf{3}$ was chosen because of a structural resemblance to $\mathbf{2}$, and being readily prepared from the parent $p$-tert-butylthiacalix[6]arene synthesized previously. ${ }^{11}$ We found that derivative 2 was an especially excellent ionophore for ethylammonium. Derivative 3 was also found to respond strongly to ethylammonium, but interference by $\mathrm{Ag}^{+}$and lipophilic organic ammonium ions, such as tetraethylammonium and hexylammonium, was great.

\section{Experimental}

\section{Reagents}

p-tert-Butylcalix[6]arene-hexaacetic acid hexaethyl ester and p-tert-butylthiacalix[6]arene-hexaacetic acid hexaethyl ester were synthesized according to procedures similar to ones described previously. ${ }^{4,11,12}$ Other chemicals were obtained from the following sources: amine ionophore I, bis(2-ethylhexyl) sebacate, and $o$-nitrophenyl octyl ether were from Fluka (Buchs, Switzerland); potassium tetrakis( $p$-chlorophenyl)borate (KTpClPB) was from Dojindo Laboratories (Kumamoto, Japan); and poly(vinyl chloride) (PVC) (degree of polymerization, 1020) was from Nacalai Tesque (Kyoto, Japan). All other chemicals were of analytical reagent grade.

\section{Electrode system}

An ethylammonium-selective electrode was constructed using PVC-based membranes, as reported previously. ${ }^{13}$ The PVC membranes had the following composition: $1 \mathrm{mg}$ of ionophore, $20 \mathrm{~mol} \%$ of $\mathrm{KT} p \mathrm{ClPB}$ relative to the ionophore, $60 \mu \mathrm{l}(55 \mathrm{mg})$ of bis(2-ethylhexyl) sebacate and $30 \mathrm{mg}$ of PVC. In some instances, a sensor membrane without $\mathrm{KT} p \mathrm{ClPB}$ was prepared. The materials were dissolved in tetrahydrofuran (about $1 \mathrm{ml}$ ) and poured into a flat Petri dish $(28 \mathrm{~mm}$ in diameter). The solvent was then evaporated off at room temperature. The resulting membrane was excised and attached to a PVC tube (4 $\mathrm{mm}$ o.d., $3 \mathrm{~mm}$ i.d.) with tetrahydrofuran adhesive. For a comparison, a sensor membrane based on an ion-exchanger alone, composed of $0.5 \mathrm{mg}$ of $\mathrm{KT} p \mathrm{ClPB}, 60 \mu \mathrm{l}(55 \mathrm{mg})$ of

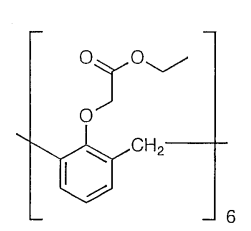

1

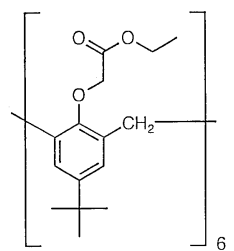

2

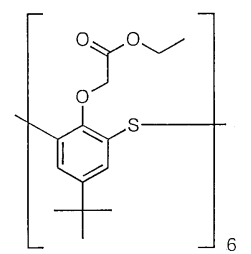

3
Fig. 1 Chemical structures of the tested ionophores. Amine ionophore I (1), p-tert-butylcalix[6]arene-hexaacetic acid hexaethyl ester (2) and p-tert-butylthiacalix[6]arene-hexaacetic acid hexaethyl ester (3).

\footnotetext{
$\doteqdot$ To whom correspondence should be addressed.

E-mail: katsu@pheasant.pharm.okayama-u.ac.jp
} 


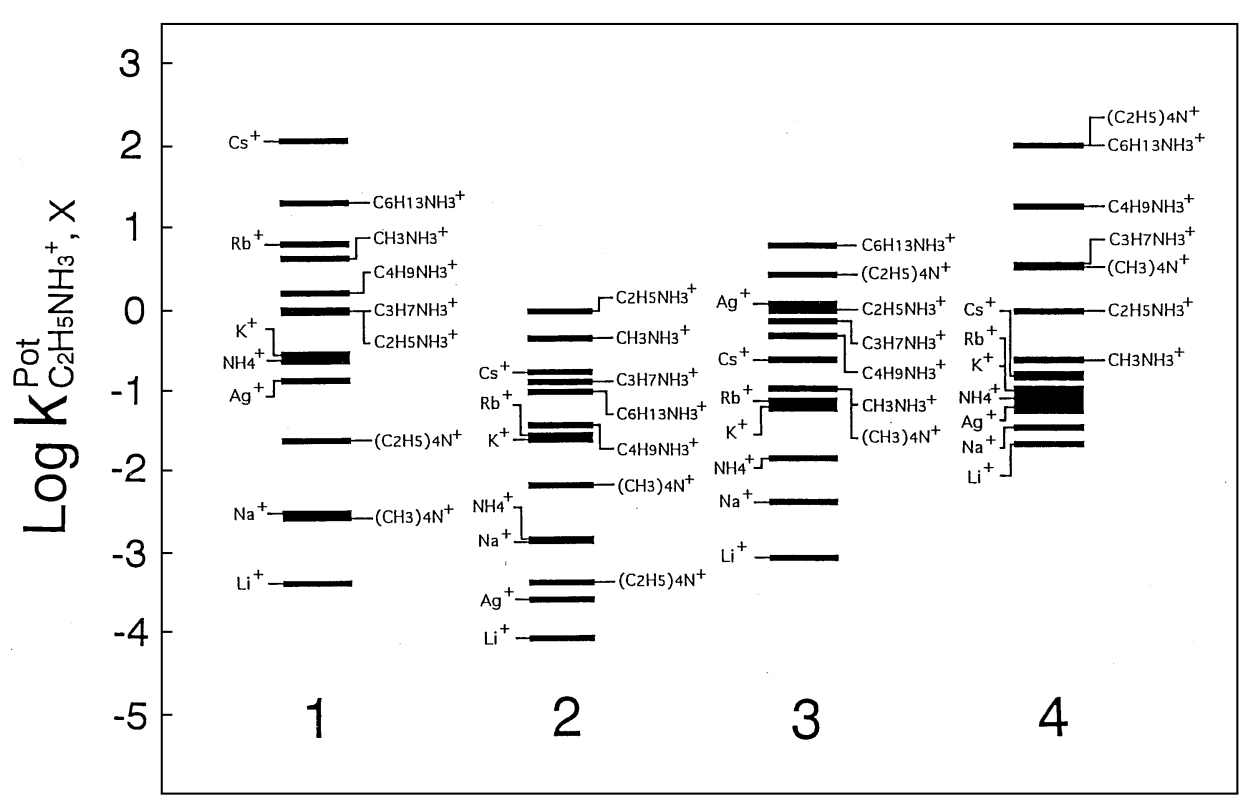

Fig. 2 Comparison of the selectivity coefficients of electrodes based on amine ionophore I (1), $p$ tert-butylcalix[6]arene-hexaacetic acid hexaethyl ester (2), p-tert-butylthiacalix[6]arene-hexaacetic acid hexaethyl ester (3), and $\mathrm{KT} p \mathrm{CIPB}(\mathbf{4})$. Bis(2-ethylhexyl)sebacate was used as the solvent mediator.

bis(2-ethylhexyl) sebacate and $30 \mathrm{mg}$ of PVC, was also prepared. The sensor membranes were conditioned overnight in a solution of $10 \mathrm{mM}$ ethylamine hydrochloride. The electrochemical cell arrangement was

$\mathrm{Ag}, \mathrm{AgCl} /$ internal solution/sensor membrane/sample solution $/ 1 \mathrm{M} \mathrm{NH}_{4} \mathrm{NO}_{3}$ (salt bridge)/10 mM KCl/Ag, AgCl.

The internal solution was the same as that used to condition the membrane. Potential measurements were made with a voltmeter produced by a field-effect transistor operational amplifier (LF356; National Semiconductor, Sunnyvale, CA, USA; input resistance, $>10^{12} \Omega$ ) connected to a recorder (LR4220E; Yokogawa, Tokyo, Japan). To examine the pHdependence of the electrode, a miniature $\mathrm{pH}$ glass electrode (1826A-06T; Horiba, Kyoto, Japan), together with test and reference electrodes, was immersed in each sample solution to simultaneously measure the solution $\mathrm{pH}$. The volume of the sample solution was $1 \mathrm{ml}$, because our electrode system was compact, as described previously. ${ }^{14}$

\section{Evaluation of the electrode performance}

The detection limit was defined as the intersection of the extrapolated linear regions of the calibration graph. ${ }^{15}$ The selectivity coefficients of the electrode $\left(k_{\mathrm{i}, \mathrm{p}}^{\mathrm{Po}}\right)$ were determined by a separate solution method ${ }^{15}$ using respective chloride salts, except for silver, for which we used nitrate salt. The concentrations were adjusted to $10 \mathrm{mM}$. The values were calculated from the equation

$$
\log k_{\mathrm{i}, \mathrm{j}}^{\text {Pot }}=\left(E_{\mathrm{j}}-E_{\mathrm{i}}\right) / S+\log c_{\mathrm{i}}-\log c_{\mathrm{j}}^{1 / \mathrm{i}_{\mathrm{i}}}
$$

where $E_{\mathrm{i}}$ and $E_{\mathrm{j}}$ represent the e.m.f. readings measured for ethylammonium and the interfering ion, respectively; $S$ is the theoretical slope of the electrode for ethylammonium $(59.2 \mathrm{mV}$ at $\left.25^{\circ} \mathrm{C}\right) ; c_{\mathrm{i}}$ and $c_{\mathrm{j}}$ are the concentrations of ethylammonium and the interfering ion, respectively; and $z_{\mathrm{j}}$ is the charge of the interfering ion. In some instances, a matched potential method ${ }^{16}$ was also applied to evaluate the selectivity coefficients. In this case, we used a fixed concentration $\left(1.0 \times 10^{-4} \mathrm{M}\right)$ of ethylammonium as the background. The selectivity coefficients were calculated from the concentration of the interfering ion that induced the same amount of potential change as that induced by increasing the concentration of ethylammonium to $2.0 \times 10^{-4} \mathrm{M}$. This measurement was performed in the presence of $0.1 \mathrm{M} \mathrm{MgCl}_{2}$ to keep the ionic strength of the solution constant; $\mathrm{MgCl}_{2}$ was chosen because the interference by magnesium was very slight. ${ }^{13,17}$ All measurements were performed at room temperature (about $25^{\circ} \mathrm{C}$ ).

\section{Results and Discussion}

\section{Selectivity of the electrodes}

Figure 2 shows the potentiometric ion-selectivity coefficients of the electrodes using the ionophores shown in Fig. 1, along with the ion-exchanger KTpClPB. The selectivity coefficients against various organic ammonium ions and inorganic cations were compared. These were determined by a separate solution method. ${ }^{15}$ An electrode made from the ion-exchanger $(4$; this number corresponds to that shown in Fig. 2) responded to primary organic ammonium ions in the order of $\mathrm{CH}_{3} \mathrm{NH}_{3}{ }^{+}<$ $\mathrm{C}_{2} \mathrm{H}_{5} \mathrm{NH}_{3}{ }^{+}<\mathrm{C}_{3} \mathrm{H}_{7} \mathrm{NH}_{3}{ }^{+}<\mathrm{C}_{4} \mathrm{H}_{9} \mathrm{NH}_{3}{ }^{+}<\mathrm{C}_{6} \mathrm{H}_{13} \mathrm{NH}_{3}{ }^{+}$, which paralleled the lipophilicity of these ions; also, the response to lipophilic quaternary ammonium ions, such as $\left(\mathrm{CH}_{3}\right)_{4} \mathrm{~N}^{+}$and $\left(\mathrm{C}_{2} \mathrm{H}_{5}\right)_{4} \mathrm{~N}^{+}$, was enhanced. In contrast, an electrode made from amine ionophore I (1) responded more strongly to methylammonium than to other primary alkylammonium ions, except for hexylammonium, which remarkably suppressed the response to lipophilic quaternary ammonium ions, such as $\left(\mathrm{CH}_{3}\right)_{4} \mathrm{~N}^{+}$and $\left(\mathrm{C}_{2} \mathrm{H}_{5}\right)_{4} \mathrm{~N}^{+}$. However, there was a significant interference from $\mathrm{Cs}^{+}$, in accordance with the fact that this ionophore also acts as a cesium ionophore. ${ }^{1,2,8}$ In the case of $p$ tert-butylcalix[6]arene-hexaacetic acid hexaethyl ester (2), the electrode responded in the order of $\mathrm{C}_{4} \mathrm{H}_{9} \mathrm{NH}_{3}{ }^{+}<\mathrm{C}_{6} \mathrm{H}_{13} \mathrm{NH}_{3}{ }^{+}<$ $\mathrm{C}_{3} \mathrm{H}_{7} \mathrm{NH}_{3}{ }^{+}<\mathrm{CH}_{3} \mathrm{NH}_{3}{ }^{+}<\mathrm{C}_{2} \mathrm{H}_{5} \mathrm{NH}_{3}{ }^{+}$, remarkably suppressing the 
Table 1 Comparison of the electrode performance in response to ethylammonium ${ }^{\mathrm{a}}$

\begin{tabular}{lcc}
\hline \multicolumn{1}{c}{ Ionophore } & $\begin{array}{c}\text { Slope/ } \\
\mathrm{mV} \text { per decade }\end{array}$ & $\begin{array}{c}\text { Detection limit/ } \\
\mu \mathrm{M}\end{array}$ \\
\hline $\begin{array}{l}\text { Amine ionophore I (1) } \\
p \text {-tert-Butylcalix[6]arene- } \\
\text { hexaacetic acid hexaethyl } \\
\begin{array}{l}\text { ester (2) } \\
p \text {-tert-Butylthiacalix[6]arene- } \\
\text { hexaacetic acid hexaethyl } \\
\text { ester (3) }\end{array}\end{array} 5^{-57.4}$ & 7 \\
\hline
\end{tabular}

a. Bis(2-ethylhexyl) sebacate was used as the solvent mediator. All measurements were performed in the concentration range of $1 \times 10^{-8}$ to $1 \times 10^{-2} \mathrm{M}$ ethylamine hydrochloride in the presence of $0.1 \mathrm{M}$ $\mathrm{MgCl}_{2}$.

b. Determined from the linear range of $2 \times 10^{-5}$ to $1 \times 10^{-2} \mathrm{M}$, except for $p$-tert-butylthiacalix[6]arene-hexaacetic acid hexaethyl ester (3) (5 $\times 10^{-6}$ to $1 \times 10^{-2} \mathrm{M}$ ).

response to hexylammonium and $\mathrm{Cs}^{+}$. A characteristic feature is that ionophore $\mathbf{2}$ afforded the strongest response to ethylammonium among various organic ammonium ions. Such an enhanced response to ethylammonium would be induced by including a non-polar ethyl group in the hydrophobic cavity of calix[6]arene with tert-butyl substituents, because the lipophilic cavities of calix[6]arenes were generally known to be quite suitable for including non-polar moieties of organic ammonium ions. ${ }^{3,4}$ Although p-tert-butylthiacalix[6]arene-hexaacetic acid hexaethyl ester (3) was also found to respond strongly to ethylammonium, interference by inorganic cations, such as $\mathrm{Ag}^{+}$, and lipophilic organic ammonium ions, such as tetraethylammonium and hexylammonium, was large. Ionophore $\mathbf{3}$ has a sulfur atom, the presence of which is generally known to enhance the response to $\mathrm{Ag}^{+}$and lipophilic organic ammonium ions. ${ }^{1,2,18-22}$

To cross-check the values of the selectivity coefficients, we measured the selectivity coefficients against organic ammonium ions for ionophore 2 using a matched potential method (log $k_{\mathrm{C}_{2} \mathrm{H}_{5} \mathrm{NH}_{3}+}^{\mathrm{Pot}^{+} \mathrm{X}}: \mathrm{CH}_{3} \mathrm{NH}_{3}{ }^{+},-0.1 ; \mathrm{C}_{3} \mathrm{H}_{7} \mathrm{NH}_{3}{ }^{+},-0.7 ; \mathrm{C}_{4} \mathrm{H}_{9} \mathrm{NH}_{3}{ }^{+},-1.1$; $\left.\mathrm{C}_{6} \mathrm{H}_{13} \mathrm{NH}_{3}{ }^{+},-0.7 ;\left(\mathrm{CH}_{3}\right)_{4} \mathrm{~N}^{+},-2.6 ;\left(\mathrm{C}_{2} \mathrm{H}_{5}\right)_{4} \mathrm{~N}^{+},-2.9\right)$. These values were similar to those obtained by a separate solution method.

\section{Sensitivity of the electrodes}

Calibration graphs were then obtained for the electrodes by measuring known amounts of ethylamine hydrochloride added to $0.1 \mathrm{M} \mathrm{MgCl}_{2}$, and plotting the concentrations against the corresponding potential readings. A high concentration of $\mathrm{MgCl}_{2}$ was added to adjust the ionic strength of the solution; ${ }^{13,17}$ $\mathrm{MgCl}_{2}$ was chosen because the interference from magnesium was slight $\left(\log k_{\mathrm{C}_{2} \mathrm{H}_{5} \mathrm{NH}_{3+}, \mathrm{Mg}_{2+}}^{\mathrm{Pot}_{2}}<-4\right)$. The measurements were performed in the concentration range of $1 \times 10^{-8}$ to $1 \times 10^{-2} \mathrm{M}$ ethylamine hydrochloride. As indicated in Table 1, all of the ionophores tested in this study gave near-Nernstian responses to ethylammonium, and $\mathbf{3}$ showed the highest sensitivity to ethylammonium. The slope within the linear range and the detection limit for $\mathbf{2}$, which afforded the highest selectivity for ethylammonium, were $57.7 \mathrm{mV}$ per concentration decade and 7 $\times 10^{-6} \mathrm{M}$, respectively.

\section{Other response characteristics}

The response time (90\% of the final signal) of the electrode using ionophore 2 was below $10 \mathrm{~s}$ when the concentration of ethylamine hydrochloride was changed from 10 to $100 \mu \mathrm{M}$.

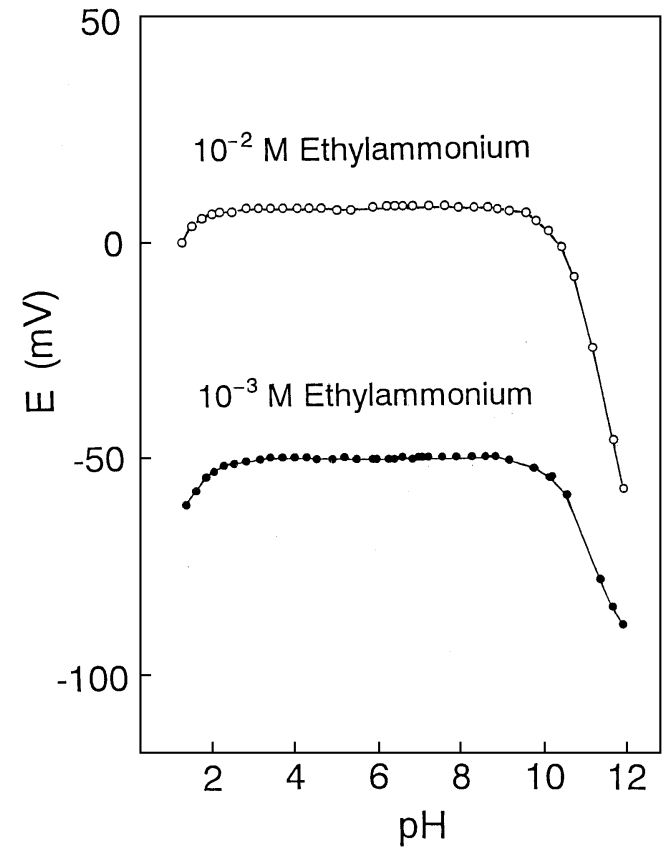

Fig. 3 Effects of the $\mathrm{pH}$ on the response of the electrode based on p-tert-butylcalix[6] arene-hexaacetic acid hexaethyl ester to ethylammonium. Bis(2-ethylhexyl) sebacate was used as the solvent mediator.

Changing the solvent mediator from bis(2-ethylhexyl)sebacate to $o$-nitrophenyl octyl ether increased the interference by lipophilic organic ammonium ions, such as $\left(\mathrm{C}_{2} \mathrm{H}_{5}\right)_{4} \mathrm{~N}^{+}$, similar to the case for other organic ammonium ion-selective electrodes developed to date. ${ }^{13,17}$ When KT $p$ CIPB was eliminated from the membrane containing $\mathbf{2}$, both the selectivity and the sensitivity of the electrode decreased markedly. This result was consistent with the view that the presence of an ionic additive in the membrane phase is important for enhancing the electrode response. $^{23}$

\section{pH-dependence of the electrode}

We examined the $\mathrm{pH}$-dependence to determine the effective $\mathrm{pH}$ range for the electrode using ionophore 2 . The $\mathrm{pH}$ of the solution was adjusted by adding an appropriate amount of dilute hydrochloric acid or sodium hydroxide solution. The ionic strength of the solution was adjusted by adding $0.1 \mathrm{M} \mathrm{CaCl}_{2}$ instead of $0.1 \mathrm{M} \mathrm{MgCl}_{2}$, because $\mathrm{Mg}(\mathrm{OH})_{2}$ is deposited at $\mathrm{pH}$ values above 9.13,17 As shown in Fig. 3, the electrode response was independent of the $\mathrm{pH}$ over the $\mathrm{pH}$ range of $2.5-9.5$. The decrease in potential above $\mathrm{pH} 9.5$ was attributable to an increase in the concentration of unprotonated amine, as the $\mathrm{p} K_{\mathrm{a}}$ of ethylamine has been reported to be 10.6. ${ }^{24}$ The decrease in potential below pH 2.5 may be due to the protonation of $\mathbf{2}$ in the membrane phase, resulting in a loss of the ability to complex with ethylammonium. A similar observation was made with a methylammonium electrode using calix[4]arene-crown-6 conjugate. ${ }^{13}$

These results demonstrated that p-tert-butylcalix[6]arenehexaacetic acid hexaethyl ester is a new ionophore for constructing an ethylammonium-selective membrane electrode, and is the first ionophore to recognize ethylammonium among various organic and inorganic ions. 


\section{Acknowledgements}

We are grateful to Cosmo Oil Co., Ltd. for supplying p-tertbutylcalix[6]arene-hexaacetic acid hexaethyl ester and p-tertbutylthiacalix[6]arene-hexaacetic acid hexaethyl ester. This work was supported by the Okayama Foundation for Science and Technology, the Wesco Science Promotion Foundation, and the Japan Society for the Promotion of Science.

\section{References}

1. P. Bühlmann, E. Pretsch, and E. Bakker, Chem. Rev., 1998, 98, 1593 .

2. R. Ludwig, Fresenius J. Anal. Chem., 2000, 367, 103.

3. K. Odashima, K. Yagi, K. Tohda, and Y. Umezawa, Anal. Chem., 1993, 65, 1074.

4. W. H. Chan, K. K. Shiu, and X. H. Gu, Analyst, 1993, 118 , 863.

5. M. Giannetto, G. Mori, A. Notti, S. Pappalardo, and M. F. Parisi, Anal. Chem., 1998, 70, 4631.

6. N. V. Shvedene, M. Y. Nemilova, V. V. Kovalev, E. A. Shokova, A. K. Rozov, and I. V. Pletnev, Sens. Actuators $B, 1995,26-27,372$.

7. K. Odashima, K. Yagi, K. Tohda, and Y. Umezawa, Bioorg. Med. Chem. Lett., 1999, 9, 2375.

8. Fluka Chemika Selectophore ${ }^{\circledR}$, 1996, Fluka, Buchs,
Switzerland.

9. T. Katsu, D. Xu, K. Tsuji, and T. Nagamatsu, Anal. Chim. Acta, 1997, 354, 301.

10. T. Katsu, M. Akagi, T. Hiramatsu, and T. Tsuchiya, Analyst, 1998, 123, 1369.

11. N. Iki, C. Kabuto, T. Fukushima, H. Kumagai, H. Takeya, S. Miyanari, T. Miyashi, and S Miyano, Tetrahedron, 2000, 56, 1437.

12. M. A. McKervey, E. M. Seward, G. Ferguson, B. Ruhl, and S. J. Harris, J. Chem. Soc., Chem. Commun., 1985, 388.

13. T. Katsu and M. Matsumoto, Anal. Sci., 2001, 17, 721.

14. T. Katsu, H. Kobayashi, and Y. Fujita, Biochim. Biophys. Acta, 1986, 860, 608.

15. R. P. Buck and E. Lindner, Pure Appl. Chem., 1994, 66, 2527.

16. Y. Umezawa, K. Umezawa, and H. Sato, Pure Appl. Chem., 1995, 67, 507.

17. T. Katsu, K. Ido, and K. Kataoka, Anal. Sci., 2001, 17, 745.

18. J. Casabó, F. Teixidor, L. Escriche, C. Viñas, and C. PérezJiménez, Adv. Mater., 1995, 7, 238.

19. T. Katsu and D. Xu, Anal. Lett., 1998, 31, 1979.

20. D. Xu and T. Katsu, Anal. Chim. Acta, 2001, 443, 235.

21. T. Katsu and H. Hirodo, Anal. Chim. Acta, 1999, 396, 189.

22. T. Katsu and H. Hirodo, Anal. Sci., 2000, 16, 789.

23. E. Bakker, P. Bühlmann, and E. Pretsch, Chem. Rev., 1997, 97, 3083.

24. "Lange's Handbook of Chemistry", ed. J. A. Dean, 11th ed., 1973, McGraw-Hill, New York. 